\title{
Facing the Crisis: Toward a New Humanistic Synthesis for Business
}

\author{
Domènec Melé \\ Antonio Argandoña \\ Carlos Sanchez-Runde
}

The economic slowdown, still ongoing in many countries, has brought about dramatic consequences. These continue to be clearly felt in many countries: mass foreclosures and evictions, non-recoverable debts, extreme difficulties for individuals and businesses to obtain credit, bankruptcies, lack of confidence from investors and downturns in stock markets around the world, bailouts from governments to banks and other financial institutions in danger of failing in an attempt to save them from insolvency or to avoid contagion. In a globalized world, no financial institution has escaped damage, and many ordinary people around the world are suffering the painful impact. With the dramatic increase in unemployment, and substantial financial commitments of states toward the financial system, public expenditure has progressively increased to the point at which the financial solvency of entire countries is at risk.

Since 2008, and even before, the word "crisis" has been on everyone's lips. Many people continue to suffer the consequences of this crisis. The causes were complex. There is abundant literature which cites exclusively "technical" reasons: the housing bubbles, evaluation tied to real estate pricing, deficient regulation and so on. Frequently, the remedies proposed are also only "technical," basically suggesting more regulation and more public control. However, a deeper reflection on the causes of the current crisis indicates that they include not only techno-economic aspects, but also behavioral, moral, and cultural aspects, all of which are closely interrelated.

In fact, the current crisis would probably not have occurred without certain political decisions, related to monetary and economic policies, and deficient regulation and monitoring. We should not overlook, however, the personal decisions related with corporate strategies and business policy, including strong incentives associated with short-term profits, and mortgage-backed securities trading involving a manifest lack of transparency. Nor should we forget the credit rating agencies and a number of different professionals, civil servants and politicians involved in some way in the unfolding of the crisis. It seems that this morass arose not only through insufficient and inadequate structures but also because of faulty human behavior and moral character. As Lewis et al. (2010) pointed out, prudence and ethics were pushed aside as greed overcame good judgment among mortgage lenders nationwide. Of course we can find large-scale failure of regulation and government policy in the origin of the crisis, but also negligence and greed on the part of the different actors empowered in the process.

In addition, we must bear in mind that business and economics do not operate within a cultural vacuum, but within a cultural environment with ideologies, values, and common practices. It is probably fair to say that the current crisis is not independent of a set of mainstream managerial and economic theories based on the homo oeconomicus as a model of the human being, and a view of business and business organizations exclusively through an economic lens. Furthermore, in recent decades, it has been quite common to consider the manager as a mere agent of the principal rather than a real professional, with skills and a strong sense of responsibility and accountability. Following this path, it has not been rare to reduce human relations to simple transactions. This leads to people being considered exclusively as resources for gains, with no thought given to reciprocity, and even less to gratuity, unless this can be clearly profitable. All of these aspects are interrelated and indicate our necessity for a more humanistic and holistic vision of business and management. 
Facing the crisis was and continues to be a challenge. "Facing" and "crisis" are two words full of meaning. Facing means confronting or affronting; literally "to strike on the forehead." A crisis is a situation within a process which deserves particular attention. Originally, the word "crisis" (krisis in Greek) was used by Hippocrates and Galen to identify a "turning point in a disease", , but not necessarily for the worse; it could be for the better too. Later, crisis became a notion employed in a great variety of fields, including psychology, economics and sociology. One current meaning of crisis in the socio-economic context is often associated with economic recession, but in more general terms, crisis means a period of time or state of affairs in which highly undesirable outcomes appear and a decisive change is impending.

We considered facing the crisis as an introduction to the topic of the 16th International Symposium "Ethics, Business and Society" which was held by IESE Business School, University of Navarra, Spain on 13-15 May, 2010. This special issue includes a selection of articles presented in this Symposium. But the topic as a whole was more than facing the crisis. It also included the idea of moving toward a new humanistic synthesis for business. Why?

Facing the crisis prompted us to reflect on the lessons that we can learn from such a situation; and what might be an appropriate direction for the future. Sen (2009), Nobel Economy Prize Laureate, suggested that "ideas about changing the organization of society in the long run are clearly needed, quite apart from strategies for dealing with an immediate crisis." But he also emphasized that a crisis is an opportunity to re-think the future: "A crisis not only presents an immediate challenge that has to be faced. It also provides an opportunity to address longterm problems when people are willing to reconsider established conventions." And added: "What is also needed is a clearheaded perception of how different institutions actually work, and of how a variety of organizations - from the market to the institutions of the state - can go beyond short-term solutions and contribute to producing a more decent economic world." The importance of doing business embedded with ethical values and a stronger sense of cooperation was pointed out in the Manifesto Global Economic Ethic - Consequences for Global Businesses, launched in 2009 during a business ethics symposium at United
Nations Headquarters. In its Preamble we read: "For the globalization of economic activity to lead to universal and sustainable prosperity, all those who either take part in or are affected by economic activities are dependent on a values-based commercial exchange and cooperation. This is one of the fundamental lessons of today's worldwide crisis of the financial and product market.",

Another widely respected moral voice was heard in 2009: Pope Benedict XVI, who published his Encyclical-Letter ${ }^{3}$ Caritas in veritate on June 29 and delivered it to the G-20 group a few days later. In this document (n. 21) he wrote: "The complexity and gravity of the present economic situation rightly cause us concern, but we must adopt a realistic attitude as we take up with confidence and hope the new responsibilities to which we are called by the prospect of a world in need of profound cultural renewal, a world that needs to rediscover fundamental values on which to build a better future." And added: "The current crisis obliges us to re-plan our journey, to set ourselves new rules and to discover new forms of commitment, to build on positive experiences and to reject negative ones. The crisis thus becomes an opportunity for discernment, in which to shape a new vision for the future" (italics in the original).

In this Encyclical-Letter, the head of the Roman Catholic Church, addressing all people of good will, dealt with many important topics which require further reflection, including ethics in globalization, the foundations of business ethics, the role of reciprocity and gratuitousness in economic activity, the necessity to consider ethics in every phase of the economic process, and the managerial responsibility toward stakeholders. One passage of this document (n. 21) seemed to us particularly inspirational in facing the crisis:

The different aspects of the crisis, its solutions, and any new development that the future may bring, are increasingly interconnected, they imply one another, they require new efforts of holistic understanding and a new humanistic synthesis. (Italics in the original)

Drawing from these latter words, the Symposium organizers found the definitive topic for the conference: "Facing the crisis: towards a new humanistic synthesis." We thought that introducing a holistic understanding of economics and business and, above all, developing a new humanistic synthesis for business 
was a real challenge. Actually, many current developments of business and management are not holistic but economic-centered, and the incorporation of other dimensions, including ethics, on the occasions that this does take place, is often as a mere complement and subordinated to economic goals.

In addition, it is still quite common in management to base arguments on the so-called "separation thesis," which leads one to consider only economic facts and to leave aside the human and ethical dimension of business. Some try to overcome such separation by adding ethical judgments, but this is used as a mere constraint on business decisionmaking, not something at the core of a decision and a guide for human flourishing.

Humanistic synthesis should not be interpreted as a naïve view which, by emphasizing the human and ethical dimension of business, forgets its economic dimension. Neither is it a mere mix of elements with no intrinsic connection between them; nor a normative addition of ethical standards. Rather it is a combination of parts or elements which form a whole. This requires a new vision of ethics and business ethics which is not limited to ethical issues and dilemmas. Understanding ethics as a code or a set of duties, or as a tool for a calculative evaluation of consequences, e.g., in utilitarian terms, can hardly be part of a solid humanistic synthesis. A different perspective is seeing ethics as an inherent dimension of human action and consequently, of economic activity.

Three articles included in this issues deal with the "separation thesis" from different perspectives and posit alternatives. Edwin M. Hartman, like MacIntyre, rejects the "separation thesis" and states that if social scientists take natural science as a model, they may err in their predictions and may offer facile ethical views. However, Hartman disagrees with MacIntyre's pessimistic view about business. He argues that Aristotle's views of the good life and of the close relationship between internal and external goods provide a corrective to MacIntyre. Finally, Hartman suggests that virtues can support social capital and thus prevail within and among firms in competitive markets.

In his article, Miguel Alzola focuses on academic research on business ethics, which includes two perspectives: descriptive and normative. He examines the status of both the "separation thesis" and its alternative, the "Integration Thesis." The latter states that it makes no sense to talk about business without talking about ethics. He argues that neither of these theses is entirely accurate. Instead, he proposes a "reconciliation project," in which the identity of both descriptive and normative domains is respected.

The third article, written by Wolfgang Grassl and André Habisch, addresses the tenuous relationship between economics and ethics. They reflect on several insights from the Caritas in veritate and its proposal for a new humanistic synthesis. They emphasize that this Encyclical gives great relevance to economic arguments and points out the interdependence of ethics and economic activity and their ontological connectedness. They defend the position that it is the proper ordering of means toward the end of integral human development that allows mankind to leave behind the vicious circle of consumerism and enter a virtuous circle that applies the creativity fostered by markets. They conclude by saying that this vision entails a new model of business management that integrates considerations of vocation, purpose, and values, and present some characteristics of such management.

The fourth article is a conceptual article by Heiko Spitzeck which also tries to reconcile economic and moral arguments. To this end, he proposes an integrative model of humanistic management and suggests prospective lines of empirical research especially in the area where business conduct is profitable but not humanistic.

The following two articles advance toward a new humanistic synthesis by considering the relational aspect of business relationships. Sandrine Frémeaux and Grant Michelson propose extending the dominant logic of exchange in business, by introducing the idea of the existential gift. This is disconnected from calculation and intent. It is characterized by the lack of right, guarantee, or any kind of hope for profit. Existential gift is driven by generosity expressed in both tangible and intangible ways. They argue that the existential gift provides human actors with greater freedom in their choices and relationships. Such "ethic of generosity" can be a source for significant progress in developing more human models and practices in business.

On his part, Antonio Argandoña posits the question of whether the traditional theories of the firm leave room for love in business organizations, 
beyond contractual relationships. His answer is in the negative, and this may be because often love is understood only as an emotion or feeling, not as a virtue. Another explanation may be that economic efficiency and profit making are considered to be incompatible with the practice of charity or love. The author tries to show that love can and should be lived in firms. Argandoña's arguments are based on considering a human action theory within the organization. He finds that love is a requirement for firms to operate efficiently, be attractive to those who take part in them, and act consistently in the long run.

Javier Aranzadi suggests that the dynamics of the structure of human action enable us to link the organizational level of institutions, norms, and culture of the firm which enhance and uphold the possibilities of individual action based on personal virtues. He adds that, at the organizational level, the existing institutions and culture are the necessary context of our individual action. But, at the individual level, we focus on the external consequences of our acts. It is our acts that maintain social institutions and culture. He argues that an ethics of personal virtues demands an ethics of institutions, the ethics which deals with the institutional means of realizing individual ends.

The article by Michael Pirson and Shann Turnbull starts with a reexamination of current governance structures, specifically those of unitary boards after the financial crisis of 2008. Instead of the existing governance structures, which are based on a paradigm of business rooted in economics, they propose a more humanistic paradigm based on network-oriented governance structures. The authors argue that, in addition to being more humanistic, this latter paradigm introduces a division of power via multiple boards, checks and balances, and active stakeholder engagement.

The last article by Michael S. Aßländer deals with Corporate Social Responsibility, focusing on its technical and political perspectives. CSR leaves unclear whether such corporate contributions to solving environmental and societal problems must be seen as voluntary additional services or whether corporations bear specific duties in this field. Based on the tenet of subsidiarity, the article emphasizes that the common interpretation of CSR should be extended by a third perspective that addresses corporations as intermediate actors bearing specific subsidiary co-responsibilities in society.
The road to a new humanistic synthesis for business is a long one. The articles of this special issue can hopefully be a step along the way.

\section{Notes}

1 Online Etymology Dictionary: www.etymonline. $\mathrm{com} /$ index.php? search $=$ crisis\&searchmode $=$ none.

2 The first signatories of this Manifesto were relevant personalities, such as Michel Camdessus, Gouverneur honoraire de la Banque de France, Hans Küng, President, Global Ethic Foundation, Mary Robinson, President, Realizing Rights: The Ethical Globalization Initiative, Jeffrey Sachs, Director, The Earth Institute, Columbia University and Desmond Tutu, Archbishop emeritus and Nobel Peace Prize Laureatea.

3 Encyclical-Letters are major documents of the Catholic Church addressed not only to Catholics but to all people of good will. Caritas in veritate deals with the crisis, but also presents significant insights on other current crucial topics related to ethics in the economics and business fields.

\section{References}

Benedictus XVI: 2009, Letter-Encyclical 'Caritas in Veritate', http://www.vatican.va/holy_father/benedict_xvi/ encyclicals/documents/hf_ben-xvi_enc_20090629_ caritas-in-veritate_en.html. Accessed 12 Nov 2010.

Lewis, V., K. D. Kay, C. Kelso and J. Larson: 2010, 'Was the 2008 Financial Crisis Causes by Lack of Corporate Ethics?', Global Journal of Business Research 4(2), 77-84.

Manifesto Global Economic Ethic - Consequences for Global Businesses: 2009, http://www.unglobalcompact.org/ docs/news_events/9.1_news_archives/2009_10_06/ Global_Economic_Ethic_Manifesto.pdf. Accessed 13 Nov 2010.

Sen, A.: 2009, 'Capitalism Beyond the Crisis', The New York Review of Books, vol. 26, no. 5 (March 26), http:// www.nybooks.com/articles/22490. Accessed $12 \mathrm{Nov}$ 2010.

\author{
IESE Business School, \\ University of Navarra, \\ Barcelona, Spain \\ E-mail:mele@iese.edu
}

